\title{
The New Focus of Global Media Ethics - Information Access
}

\author{
$\operatorname{Ran} \mathrm{Gao}^{1, *}$ \\ ${ }^{1}$ Faculty of Journalism and Communication, Communication University of China, Beijing, China \\ *Corresponding author. Email: dr.gao.ran@foxmail.com
}

\begin{abstract}
In the global context of profound changes in the international situation and media ecology, media ethics are facing great challenges. It is urgent for media ethics to adapt to the changes of the times. In order to understand the current trends in the development of global media ethics, the author conducts a semantic network analysis of the texts of current media ethics norms in countries and regions of five continents $(\mathrm{N}=21)$, and finds that "information access" is probably the key to solve the dilemma of contemporary global media ethics. The access to information not only responds to the demands of the times, but also is the essence of the game between the existence and the abandonment of the Internet neutrality. It still needs further results of complexity research to be truly protected.
\end{abstract}

Keywords: media ethics, access to information, global journalism norms, semantic network analysis

\section{INTRODUCTION}

The development of human society is constantly accompanied by numerous ethical dilemmas, and new technologies that are constantly invented have not completely changed this situation. Moreover, people's use of technology is not only constrained by the inherent properties of technology, but also naturally restricted by the cultural ideas that people hold [1]. Faced with the complexity of the problem, the development of research is based on qualitative and quantitative analysis methods, including speculative research, literature analysis, and semantic network analysis. The study found that in the global media ethics norms, access to information has become a common focus compared to some of the more scattered concerns.

\section{THE RISE OF ACCESS TO INFORMATION} AND GLOBAL MEDIA ETHICS

After combing the relevant literature [2] collected by Chinese and foreign scholars, it is found that the existing academic results not only analyze the connotation and extension [3] of the concept of "access to information" [4], but also divide the three methods of access to information, that is, the physical access, intellectual access, and social access [5]. In addition, some talks about access to information and affordability from the perspective of solving the digital divide, [6] while others study access to information and communication in the policy making process of the EU's political system. [7] These early researches on "access to information" are undoubtedly quite meaningful, but unfortunately, it is very rare to investigate the connection between access to information and media ethics in the era of globalization.

The author deduces the logical relationship among media ethics, ethics, morality, media ethics and moral norms, semantic network analysis, and access to information (see "Fig. 1"):

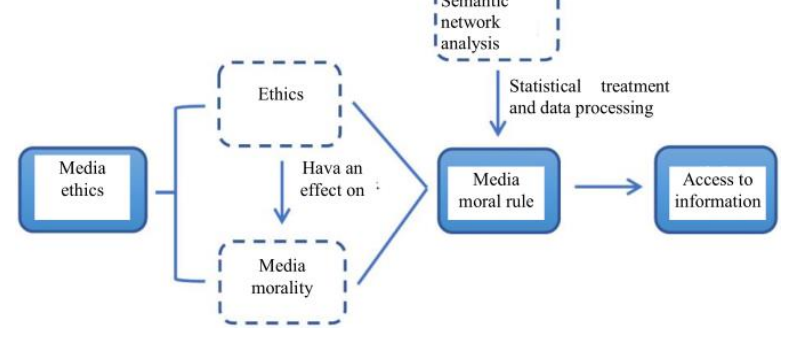

Fig. 1. From "media ethics" to "access to information". 


\section{THE SEMANTIC NETWORK ANALYSIS PRESENTS THE CORE ETHICAL VALUE OF GLOBAL MEDIA TODAY}

If it is said that the theoretical logic of this article may fit some dimensions of Weber's research ideas ${ }^{1}$, but in terms of research methods, it is exactly the opposite of Weber's research methods. To be specific, the author collected from the Internet the latest text of professional ethics in the most highly regulated news media (newspapers, radio and television), which were officially published in 21 countries and regions ${ }^{2}$ on five continents. After that, the text was organized, data was cleaned and the data was analyzed with software AutoMap ${ }^{3}$ and $\mathrm{ORA}^{4}$.

After text mining and network analysis, the author found that some of the basic values that people have long cherished have in fact not only been marginalized globally ("Fig. 2"), but some chain reactions have also been produced-for example, the marginalization of "public interest" has in effect dispelled public power. As shown in "Fig. 2", "society" has been pushed to a surprising marginal zone, close to the "exceptions" situation. At the same time, "citizen", "officials" and "privacy" lack the necessary connections with other terms, that is to say, they are on the outer edge of the network. Therefore, the global neglect of public interest, privacy, society, officials and citizens may put the prospect of human development at risk.

Through semantic network analysis, it is found that in daily life, having a transparent will and providing reliable information is often associated with many virtues, such as honesty, authenticity, and integrity. As shown in "Fig. 3", paired ideas such as "freedom of expression" / "national security", "government" / "individual" (individual) can be easily found because of frequency of occurrence. These paired ideas demonstrate the core relationships in global media ethics that require mediation. In addition, "transparency", "participation" and "respect" also show high-frequency characteristics, and together with

For example, Weber has claimed that he did not pay attention to the things shown to us theoretically and officially in the ethics handbooks, although he acknowledged that these things had a great practical significance through the influence of church discipline, pastor work, and preaching. Max Weber, Protestant Ethics and the Spirit of Capitalism, Beijing: Peking University Press, 2014, p. 96.

These countries and regions include Australia and New Zealand in Oceania; South Africa, Egypt, Congo, Kenya in Africa; Norway, Portugal, France, Britain, and Germany in Europe; Canada, the United States, Peru, and Brazil in the Americas; and Hong Kong, Thailand, Bhutan, South Korea, Japan, and India in Asia.

AutoMap is a text mining tool developed by the Computing and Analysis Group (CASOS) of Carnegie Mellon University's Social and Organizational System.

4 ORA is a tool for network analysis and visualization developed jointly by Carnegie Mellon University and Netanomics. "access to information", constitute an important ethical value in the global media ethics regulation.

Although the recent use or access of technology provides a more convenient way for people to understand various things, globalization defined by interconnectivity can easily lead people to mistake the media landscape as a simple technology entry and platform. [9] In fact, according to any of the sources' authority, credibility, and availability, western media are now in a dominant position in the global public opinion pattern. Therefore, what is "acceptable discourse" is still determined by the values of mainstream western society, which has led to the marginalization of voices outside the boundaries. ${ }^{5} \mathrm{At}$ the same time, the production of news content such as listening to a variety of voices and conducting fact checks is done within the overall media framework rather than outside it. [10] Therefore, truly obtaining the access to information without being overshadowed by the dominant media framework has become a consistent and urgent need for global media ethics. The experimental results found that "access to information" occupied the highest frequency in the current official media ethics texts in 21 countries and regions on five continents, instead of "human rights", "social responsibility" or any other word.

"The access to information" is an equal ethical proposition, which can provide bottom-level trust for the exchange and mutual learning of civilizations. In this sense, the access to information is a way to control technicalism and instrumentalism in global media ethics ("Fig. 3"). On the one hand, ensuring "access to information" is the key to solving the ethical problems of global media; on the other hand, this is also the result of examining the "access to information" from the perspective of global media ethics.

In 1980, the UNESCO Research Committee on International Communications published a report, "Multiple Voices, One World", calling for the establishment of a "New World Information and Communication Order" (NWICO), which sparked controversy. The United States, Britain, and Singapore have withdrawn from UNESCO successively, causing this international organization to fall into a fiscal and policy crisis. Although Britain and the United States returned to UNESCO several years later, the dispute over the new order of world information and communication has deviated from its original intention and has fallen into abeyance. 


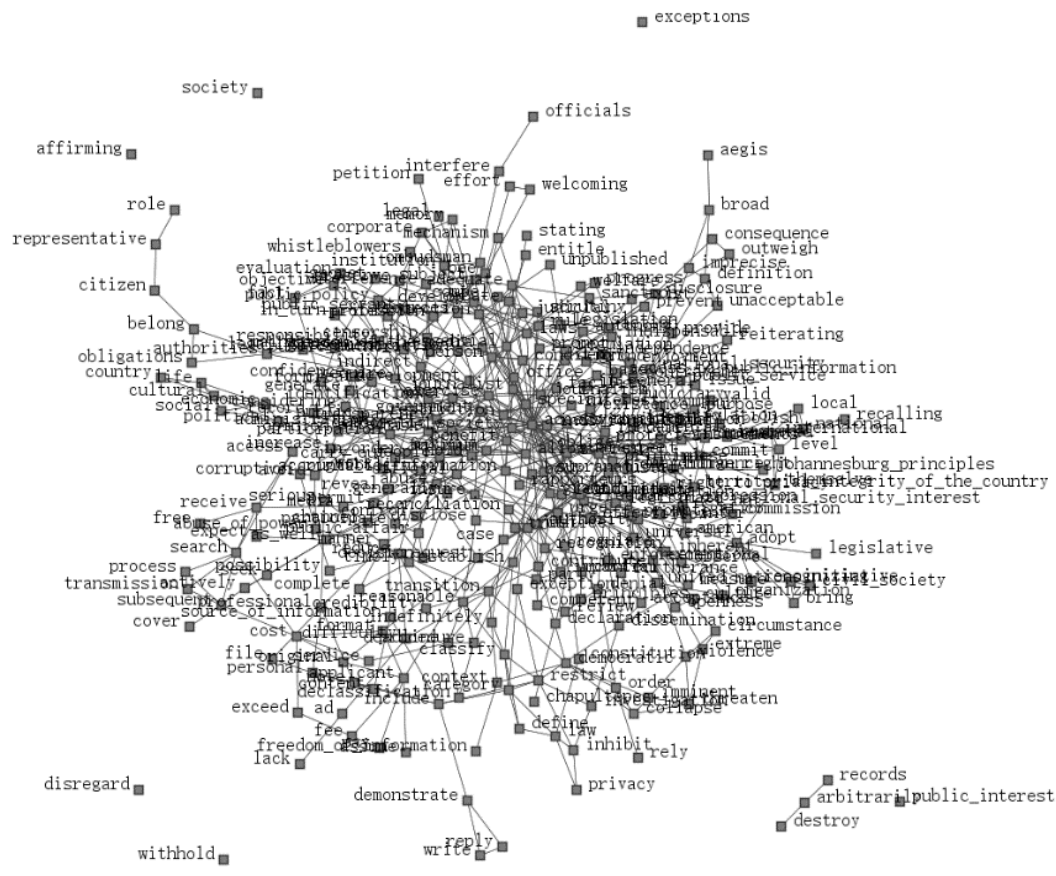

Fig. 2. The semantic network: global journalism norms [8].

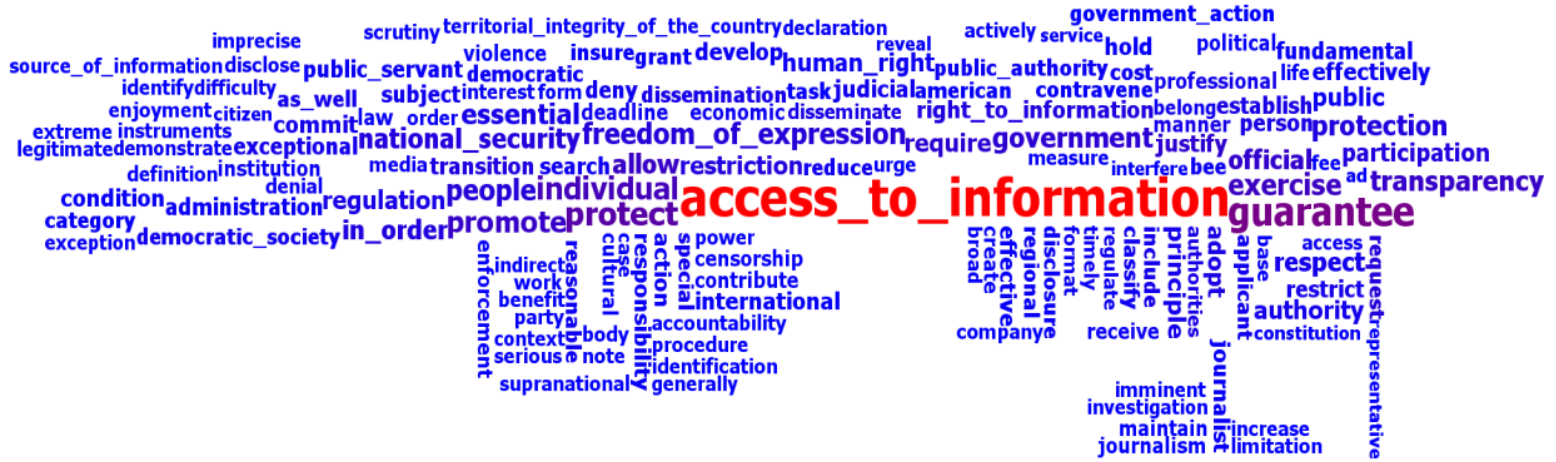

Fig. 3. Word cloud: global journalism norms [11].

\section{THE NATURE OF THE DISPUTE ON EXISTING AND ABOLISHING OF INTERNET NEUTRALITY}

It goes without saying that the information dissemination activities of media controllers attached to personal ideological tendencies, lifestyles, and political values naturally can't completely follow an impartial position, but their own social attributes are hidden in the rhetoric of objectivity. The biased value of the communicator is finally incorporated into the management system of the media industry after being institutionalized organically. [12] Therefore, under normal circumstances, the claim of the principle of neutrality in communication activities seems to lack practical logic. In daily social practice, even the western media organizations that still dominate the discourse in 
the world, the primary manifestations of their ethical norms are "political correctness" and market-driven (the former responds to the value orientation of most people in western society, and the latter, is a bit like what Ginneken described, "Who pays, who selects [13]"). The principle of information neutrality disappears, especially when it conflicts with public opinion in countries with different ideological and social or economic development levels.

But at the technical level, thinking about net neutrality has always been the present tense. In 2015, during the presidency of the US President Obama, the Federal Communications Commission (FCC) issued the "Open Internet Order" to ensure the neutrality of network data transmission. Two years later $(2017,12)$, in the presidency of President Trump, the same organization announced a partial withdrawal of the content of this cyber governance document. [14] However, more than 20 states in the US immediately announced that the principle of net neutrality was retained in their respective states. ${ }^{6}$ The Internet Industry Association and many non-governmental organizations also opposed the abolition of the Internet Neutrality Act and called on netizens to actively fight for Internet citizenship and online freedom of speech. It is found that this seemingly related to the "already dead" or "more free" debate on the Internet is essentially a game of "access to" Internet / information, although there are many competitions between commercial interests dimension and media ethics dimension.

In the practice of network communication, as a result of the game of law, technology, and social norms, the management and filtering behavior [16] of Internet information has become an effective concept relative to the access to information. People's understanding of Internet information regulation has changed a lot in the first two decades of the 21 st century. Looking back at the history of the development of the Internet, almost all North American related patents and documents [17] in the 1980s and 1990s were related to how to regulate Internet information. [18] This may be regarded as the continuation of the era of cybernetics that began to emerge in the 1940s. [19] At that time, the cybernetics founded by Wiener made information received as a "possibility", and this reception had nothing to do with the authenticity of the message content or its aesthetic significance. As a social achievement of human production, this kind of machine intelligence can't justify its own choices, without emotion, and even put all the mathematical diagrams into the black box. The birth of cybernetics is closely related to the era of the game of productivity and production relations at that time, that is, the rapid expansion of information and the forced innovation of information management

6 It includes Washington, California, New York, Connecticut, Maryland, New Jersey, Montana, and so on. technology brought about by it. However, today, two or three decades later, in terms of social ethics, the importance of access to information has greatly exceeded information filtering regulations and has become the core concern of global media norms. [20]

It is worth noting that while the dispute over the neutrality of the Internet in the United States, the concept similar to the concept of access to information - information transparency, has been preserved and developed in recent years. The pursuit of "transparency" and even its development into a culture is rooted in the pre-print culture that is older than today's electronic culture and even print culture: "Transcript culture and Gothic architecture are concerned about the transparency of light, rather than the shining of light." [21] Today, the only thing that is not controversial in the US "Open Internet Order" and is retained is the "transparency principle" (requiring Internet service providers to disclose how and when they block or slow down the flow of information, as well as the paid priority services they provide). [22] Some inheritance and some breakthrough is the law of human society in the evolution of the intricate overlap. When the original non-discriminatory principle of the Internet became precarious, the information transparency / access became a new pursuit requiring fair and reasonable use of information resources.

\section{CONCLUSION}

Media ethics is gaining more and more attention at the global level. This is because people have entered the era of globalization of communication. The development of information communication technology (ICT) and social media has made related issues increasingly acute and contradictions increasingly apparent, and at the same time, allows everyone to think about how to get out of the predicament. Media ethics issues have two governance dimensions, law and ethics. The concept of "access to information", which has not been protected by law, is an interesting discovery in the field of media ethics. Protection of access to information is likely to bring about breakthroughs in related issues. There seems to be a similar puzzle and answer relationship between media ethics and access to information. The latter not only responds to the demands of the times, but also reflects the essence of some current Internet disputes.

How does the discovery of access to information solve the dilemma of global media ethics? It needs to be acknowledged that although the access to information may not completely solve all the problems of global media ethics, it is likely to make other contradictions related to it, such as freedom / security and government / individuals less acute. Therefore, the author strongly supports a step-by-step approach. On the basis of understanding that access to information has become a 
new focus, people should start from weakening certain contradictions and finally break through the predicament of spreading global media ethics.

\section{References}

[1] John Durham Peters: SPEAKING INTO THE AIR: A History of the Idea of Communication, translated by Deng Jianguo, Shanghai: Shanghai Translation Press, 2017. (in Chinese)

[2] Lor, P. J., \& Britz, J. J. (2007). "Is a knowledge society possible without freedom of access to information?" Journal of information science, 33(4), 387-397.

[3] Ibid, 77-99.

[4] McCreadie, M., \& Rice, R. E. (1999). "Trends in analyzing access to information. Part I: Cross-disciplinary conceptualizations of access," Information processing \& management, 35(1), 45-76.

[5] Burnett, G., Jaeger, P. T., \& Thompson, K. M. (2008). "Normative behavior and information: The social aspects of information access," Library \& Information Science Research, 30(1), 56-66.

[6] He Shenggen: "Access to Information: The Solution to the Digital Divide", China Social Science News, November 20, 2013. (in Chinese)

[7] Héritier, A. (2003). "Composite democracy in Europe: the role of transparency and access to information," Journal of European public policy, 10(5), 814-833.

[8] Gao, R. (2018). "Approaches to Global Media Ethics," The 14th International Graduate Conference (not yet published), Institute of Communication Studies, Communication University of China, 6.

[9] Terhi Lantaneng: "Media and Globalization", translated by Zhang Hong, Communication University of China Press, 2016, p.148. (in Chinese)

[10] Jaap Van Ginneken: "Understanding International News: A Critical Introduction", translated by Li Hongtao, Beijing: Communication University of China Press, 2016, pp. 91-92. (in Chinese)

[11] Gao, R. (2018). "Approaches to Global Media Ethics," The 14th International Graduate Conference (not yet published), Institute of Communication Studies, Communication University of China, 8.

[12] Jaap Van Ginneken: "Understanding International News: A Critical Introduction", translated by $\mathrm{Li}$ Hongtao, Beijing: Communication University of China Press, 2016, p. 64. (in Chinese)

[13] Jaap Van Ginneken: "Understanding International News: A Critical Introduction", translated by $\mathrm{Li}$ Hongtao, Beijing: Communication University of China Press, 2016, p. 33. (in Chinese)

[14] Marguerite Reardon: "Net neutrality has been dead for a year: What you need to know", June 11, 2019, https://www.cnet.com/news/net-neutrality-is-now-reallyofficially -dead-open-internet-congress-now-what /, August 7, 2019.

[15] Roberts, M. E. (2018). Censored: distraction and diversion inside China's Great Firewall. Princeton University Press.

[16] Akl, S. G., \& Taylor, P. D. (1983). "Cryptographic solution to a problem of access control in a hierarchy," ACM Transactions on Computer Systems (TOCS), 1(3), 239-248.

[17] Gupta, A. K. (2003). U.S. Patent No. 6,516,315. Washington, DC: U.S. Patent and Trademark Office.
[18] Maigret, E. (2015). Sociologie de la communication et des médias. Paris: Armand Colin, 87.

[19] Idem, 92

[20] Sturges, P. (2009). "Access denied: the practice and policy of global internet filtering," IEEE Transactions on Professional Communication, 52(4), 413-414.

[21] McLuhan, "The Gutenberg Galaxy: The Birth of Printing Civilization", Beijing: Beijing Institute of Technology Press, 2014, p.192. (in Chinese)

[22] Gao Ran, "The Rupture of Internet Neutrality", 2018 Annual Conference of the Chinese Journalism History Society (Hangzhou) (unpublished), Communication Research Institute of Communication University of China, October 2018, pp. 1-2. (in Chinese) 